\title{
Review of the Research on Ethnic Sports Tourism in China
}

\author{
Ping $\mathrm{Li}^{1}$, Jinku Huang ${ }^{2, *}$ \\ ${ }^{1}$ School of Recreation, Sport and Tourism, Beijing Sport University, Beijing, China \\ ${ }^{2}$ Institute of Geomechanics, Chinese Academy of Geological Sciences, Beijing, China
}

\begin{abstract}
Ethnic sports culture is an important part of ethnic culture. The development of ethnic sports tourism is conducive to the intergenerational transmission and development of sports culture and the enhancement of "cultural confidence", as well as the development and utilisation of ethnic sports tourism resources. Based on an analysis of ethnic sports tourism literature in China, this paper first reviews the historical course of ethnic sports tourism research, which can be divided into three stages: exploration, development and improvement. Provincial research locations are analysed at different stages. Secondly, the main content of ethnic sports tourism research is summarised under five headings: definition, resource evaluation, development and utilisation, brand building and marketing management. The research methods used are then analysed. Finally, in order to provide a reference for the in-depth study of ethnic sports tourism in the future, the paper makes four recommendations. These include introducing pluralistic theory, focusing on stakeholders as the subject of research, improving the quantitative evaluation of ethnic sports tourism resources, and exploring the impact of ethnic sports tourism.
\end{abstract}

\section{Introduction}

Since China's reform and opening up in 1978, with rapid economic development and continuous improvement in living standards, tourist numbers have increased, as has the income they bring with them. In 2019, the number of domestic tourists in China was 6.006 billion, the number of inbound tourists was 145.31 million, and the total annual tourism revenue was 6.63 trillion Yuan [1].

Sports tourism is gradually becoming more popular in China. Since 1960, when it successfully ascended Mount Everest, the Chinese mountaineering team has led a group of exceptional outdoor sports enthusiasts on mountaineering expeditions. However, the official start of sports tourism in China was marked by the establishment in 1984 of the international sports tourism company in Tibet. In 1986, the China International Sports Tourism Corporation, established by the National Sports Commission of China, started to develop sports tourism at national level. In his 1995 report on "Several Issues Concerning the Sports Tourism Industry", the deputy director of the State Sports Commission, Zhang Faqiang, for the first time suggested that sports tourism was an industry. In 2001, the National Tourism Administration set "Sports Fitness Tour" as the theme of tourism, which promoted the development of sports tourism. The development of sports tourism in China was boosted by Beijing's hosting of the Summer Olympics in 2008, and will be further boosted by the Winter Olympics in 2022 .

In addition, a series of national policies has greatly promoted the development of sports tourism. The 2016
"Guiding Opinions on Vigorously Developing Sports Tourism", the 2018 "Guiding Opinions on Accelerating the Development of the Sports Competition Performance Industry", and the 2019 "Outline for Building a Leading Sports Nation" all mention the promotion of sports tourism.

Ethnic sports tourism is an important part of sports tourism. It includes the historical and cultural traditions of the 56 ethnic groups in China that have been passed down for thousands of years and that constitute the long historical and cultural heritage of the Chinese nation. The rational development of ethnic sports tourism can increase the types of mass tourism and experiences, and also help to transmit and carry forward ethnic sports culture and enhance its "cultural confidence".

There has been more than 20 years of academic research on ethnic sports tourism in China. This paper is based on a systematic review of 595 related literature (including journal articles, masters and doctoral papers) found by using the search terms "ethnic sports tourism" in the China National Knowledge Infrastructure database. It summarises four aspects of the progress of ethnic sports tourism research - research process, main research content, research methods, conclusion and prospects - to glean useful knowledge and promote the sustainable development of ethnic sports tourism.

\section{Research process}

Two aspects of the research process were studied, based on annual statistics on the amount of literature on ethnic sports tourism, and a case study of the literature: history

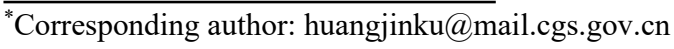


(Figure 1) and changes in the number of case studies at the provincial spatial level. The history of ethnic sports tourism research was divided into three key stages: exploration (1998-2002), development (2003-2012), and improvement (2013-present). Changes in the number and distribution of studies were analysed according to these three key stages.

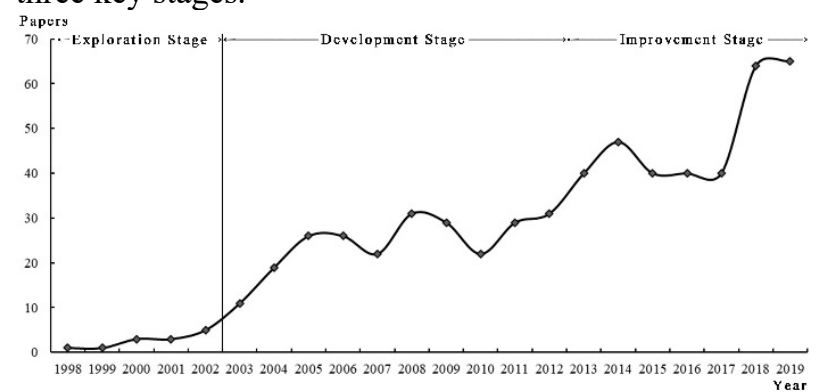

Fig 1. Research phases of "Ethnic Sports Tourism" in China.

\subsection{History}

\subsubsection{Exploration stage (1998-2002)}

At this stage, the number of papers published each year was relatively small. As can be seen from Figure 1, fewer than 5 papers were published each year, which shows that scholars were paying little attention to ethnic sports tourism in the preceding five years. Research content at this stage was mainly focused on the development of ethnic sports tourism resources [2], the industrialisation of ethnic sports tourism [3], the interactive development of ethnic sports and tourism [4], and the evaluation of ethnic sports tourism resources [5].

\subsubsection{Development stage (2003-2012)}

More documents were published annually during this stage compared with the previous one (between 10 and 30 articles). Most research focused on the development of resources for ethnic sports tourism [6], followed by research on the development of ethnic sports tourism products (projects) [7], the industrialisation of ethnic sports tourism [8], and the sustainable development of ethnic sports tourism [9]. Some scholars were also paying attention during this stage to research on the ethnic sports tourism market [10] and the ethnic sports tourism brand [11].

\subsubsection{Improvement stage (2013-present)}

By this stage, the number of papers published annually has increased, compared with the previous stage, to about 40-65 studies each year. In terms of the research content of the improvement stage, most attention is still focused on the development of ethnic sports tourism resources [12], and slightly less on the current situation of ethnic sports tourism [13]. However, there is still some research on the development of ethnic sports tourism products (projects) [14], the sustainable development of ethnic sports [15] and the evaluation of ethnic sports tourism resources [16]. The marketing of ethnic sports tourism [17] and the development model of ethnic sports tourism [18] are new research areas.

\subsection{Case study changes at provincial spatial level}

In the statistical analysis of the research literature, case studies at city and county level and below were counted as studies at provincial scale. At all three research stages, most of the key locations for ethnic sports tourism research have been provinces with large ethnic minority populations.

In the exploration stage, research on ethnic sports tourism began in Guangxi and Yunnan, but not in other regions; in the development stage, the number of studies using Guangxi as a case study increased significantly, and it was a hot location for research. In addition, there were also relatively large numbers of studies in Guizhou and Sichuan. Hunan, Xinjiang, Qinghai, Yunnan, Inner Mongolia, Hubei, Gansu, Chongqing, Hainan, Heilongjiang, Henan, Tibet, Guangdong, Liaoning, Jilin, and Hebei all also had relevant studies. At this stage, the research area expanded and most provinces began to pay attention to the development of ethnic sports tourism. In the improvement stage, Guangxi, Yunnan, and Guizhou are the main research centres, followed by Sichuan, Hunan and other regions. In addition to the research areas in the development stage, there is now research on Shanxi, Jiangxi, Shaanxi, Anhui, Ningxia, Shandong and other places. However, the most researched location is still Guangxi province. Generally speaking, the southwest has always been the main region for ethnic sports tourism, and the key locations for ethnic sports tourism research include Guangxi, Guizhou and Yunnan, among others.

\section{Main research content}

\subsection{Concept definition}

The concept of ethnic sports tourism is inseparable from the main body of "ethnic sports". Some scholars believe that Chinese ethnic sports refer specifically to martial arts and the health care system related to martial arts [19]. However, most academic researchers believe that the term "ethnic sports" refers to sports activities that are unique to one or more ethnic groups living in a certain area and widely passed down among the people, including fitness and leisure, athletic performances, folk songs and dances and other characteristics [20].

Some scholars believe that the concept of ethnic sports tourism is the sum of social, economic and cultural activities based on ethnic sports resources and sports facilities [21], or think that ethnic sports tourism is a way of life in which tourists consume folk sports, attracted by their unique sports resources and culture, based on certain specific tourism facilities [22]. From an economic perspective, some scholars believe that ethnic sports tourism is the sum of the phenomena of making money, creating employment opportunities, stimulating domestic demand, increasing local fiscal revenue, and promoting economic and cultural exchange with ethnic minority 
sports at the core [23]. From a sociological perspective, other scholars believe that ethnic sports tourism is a special kind of human social activity, not just cultural entertainment, higher-level consumption, social interaction and an important economic activity, but also a wide range of ethnic sports cultures, which can enhance people's health and physical fitness, education and training, an important way to shape a beautiful mind [24].

Generally speaking, from whatever point of view ethnic sports tourism is defined, the main emphasis is on ethnic sports projects that can be developed into tourism resources as the main tourist attraction, in which tourists mainly watch or participate in experiences, and in which static displays, sports events, folklore festival performances and other tourism activities are the main means of performance.

\subsection{Resource evaluation}

The evaluation of ethnic sports tourism resources is an important basis both for the rational use of resources and for the achievement of sustainable tourism development. Existing evaluation research is both qualitative and quantitative. Qualitatively, evaluation starts with fitness, entertainment, education, performance, competition, participation and other values of ethnic sports tourism resources [5]; quantitatively, some scholars have established an evaluation index system to evaluate whether ethnic sports are suitable for tourism development [16]. The index system established for the quantitative evaluation of ethnic sports tourism resources largely includes resource conditions [25], development potential [26], development conditions [27], stakeholders [25], and development benefits [27]. Among these, resource conditions, development potential, and development conditions are important factors for measuring whether ethnic sports projects are suitable for tourism development.

In summary, there has been no comprehensive evaluation of ethnic sports tourism resources to date. The existing academic research is mostly qualitative, and there is not enough quantitative research that uses sound methods. Compared with the evaluation research on other tourism resources, evaluation research on ethnic sports tourism resources has not formed a scientific and rational evaluation index system; nor has it played a leading role in the development and utilisation of ethnic sports tourism resources.

\subsection{Development and utilisation}

Most of the existing literature is on the development and utilisation of ethnic sports tourism, accounting for about $28 \%$ of the total. The main points of concern include development types, development models, and existing problems and solutions for ethnic sports tourism.

In terms of development types, some scholars divide ethnic sports tourism into traditional sports dance (religious, custom), traditional sports events (competitive, fitness), and traditional sports activities (entertainment) according to the different types of sport [28]. There are also scholars who begin from the perspective of the function of sports events as fun competitions, games and entertainment, beautiful dance styles, style performances, special festivals and health care [29]. From the perspective of regional styles and cultural traditions, some scholars divide China's ethnic sports tourism into a succession of ethnic festivals with sacrifice series, love series, traditional martial arts series, harvest and celebration series, water customs series, snow covered plateau series projects and grassland scenery series projects [30]. Most scholars classify ethnic sports tourism products (items) from the perspective of the characteristics or functions of ethnic sports events, which play a certain guiding role in the current development of ethnic sports tourism. However, since there is to date no consensus on classification, there is still a lack of strong theoretical support in the development of ethnic sports tourism products, and a scientific and mature product system has not yet been developed.

In terms of the development model, some scholars have proposed a "front, curtain, and backstage" model, based on the protective development of ethnic sports tourism resources and grounded in the work of Goffman (1959), who described the demarcation of performance regions into "front and backstage". They believe that its development should be based on a selective display, with the establishment of a buffer zone and protective space [31]. Others have proposed traditional and modern sports integrated development models, combined development models, ecological environment protection development models [32], and yet others believe that development models for minority sports tourism can be divided into three categories, namely a transplantation development model, a square development model and a village development model [33]. Some scholars have proposed a model of ethnic sports tourism products consisting of "idea, clues, pattern, and hierarchy" [18]. In the process of development, it is necessary to select and develop different types of ethnic sports tourism according to different resource types, resource characteristics, and market demands to form a unique development model.

Problems in the development of ethnic sports tourism can be divided into two main aspects: (1) subjective including out of date concepts [13], lack of government guidance and planning [10], insufficient investment [6], poor management and service awareness [10], and ethnic sports tourism's singular development form (mostly watching and performing) [6] and weak publicity [10]; (2) objective - including the relatively underdeveloped economic development in ethnic areas [13], the lack of professional talent engaged in ethnic sports tourism (including its current practitioners, as well as their successors) [10], poor infrastructure (tourism accommodation, catering, amusement) [13], inaccessible locations and transport [6].

Suggestions for solutions can be categorised as follows: (1) At government level, there should be scientific development planning, vocational training for employees should be strengthened [2], and the construction of infrastructure should be increased, with traffic as the primary consideration [34]; (2) At the aesthetic level, both the development of ethnic sports 
tourism boutique projects [35] and the promotion and brand building of ethnic sports tourism products should be strengthened [2]; (3) At the public level, more and better nongovernmental sports projects are needed, and the peoples' initiative should be engaged through festivals and performances, daily training, non-governmental events, spontaneous organisational training and inheritance activities and in-depth development of ethnic sports projects [35].

\subsection{Brand building}

Research on the brand building of ethnic sports tourism can be summarised as follows: (1) Analysis of the content of the brand system of traditional ethnic festival sports tourism based on the research framework of value system, management system, communication system and impression system [36]; (2) Analysis of the brand impact factors of ethnic sports tourism from the perspective of the different dimensions of support (location conditions, superiority of tourism products, abundance of related tourism products, and quality of tourism services), maintenance (local government attention, management of energy efficiency, citizen quality), and realisation (operating efficiency, investment value, other related industries) [36]; (3) The idea of ethnic sports tourism brand building is to use unique ethnic sports resources and traditional items, combine local natural resources and cultural ethnic sports resources to design distinctive tourist routes, and use ethnic traditional festivals to organise competitions [37].

On the whole, research on the brand building of ethnic sports tourism has not yet formed a mature theoretical system. Most research uses a certain region as a case study to analyse how to build a brand of ethnic sports tourism with regional characteristics. Related research focuses on description. Positioning research, brand management research, brand strategy research, brand value research, brand communication research still needs in-depth analysis.

\subsection{Marketing management}

The marketing research on ethnic sports tourism has three main aspects: marketing strategy, marketing tactics, and marketing promotion. (1) Marketing strategy is a strategic and overall program for tourism marketing. The marketing strategy for ethnic sports tourism includes government-leadership, regional unity [38], strengthening publicity and cultivating talent [39]; (2) the business activities that study the specific implementation of ethnic sports tourism marketing are marketing tactics, which mainly include channel tactics, product tactics [40], pricing tactics and geographic tactics [38]; (3) marketing promotion leans more towards how to promote ethnic sports tourism, including media promotion, festival promotion and service promotion [38].

Marketing management makes up a relatively small part of the research literature on ethnic sports tourism, and there are few applications of mature marketing theories. In addition, related topics such as the marketing model, marketing competitiveness evaluation and marketing ability of ethnic sports tourism need to be further studied.

\section{Research methods}

Most of the research thinking on China's ethnic sports tourism is based on "proposing problems - analysing problems - solving problems" and most research is qualitative, supplemented by quantitative analysis such as questionnaire surveys, analytic hierarchy processes, fuzzy comprehensive evaluation, factor analysis and cluster analysis. Quantitative research has gradually increased and appears mainly in the improvement stage, with the increase in attention to ethnic sports tourism and the overall increase in the amount of related literature. However, qualitative research still accounts for a large proportion of the literature, the amount of quantitative analysis is obviously inadequate, and the research perspective also urgently need to be broadened.

Table1. Main methods used by Chinese ethnic sports tourism research.

\begin{tabular}{|c|c|c|}
\hline Category & Methods & Research content \\
\hline \multirow[t]{5}{*}{$\begin{array}{l}\text { Qualitati- } \\
\text { ve analysis }\end{array}$} & $\begin{array}{c}\text { Case } \\
\text { analysis }\end{array}$ & $\begin{array}{l}\text { Carding, analyses problems of, and } \\
\text { countermeasures for, ethnic sports } \\
\text { tourism resources }\end{array}$ \\
\hline & $\begin{array}{c}\text { Literature } \\
\text { analysis }\end{array}$ & $\begin{array}{c}\text { Definition of concepts and summary } \\
\text { of relevant research status }\end{array}$ \\
\hline & $\begin{array}{l}\text { SWOT } \\
\text { analysis }\end{array}$ & $\begin{array}{c}\text { Analyses the strengths, weaknesses, } \\
\text { opportunities and challenges of } \\
\text { ethnic sports tourism }\end{array}$ \\
\hline & $\begin{array}{c}\text { RMP } \\
\text { analysis }\end{array}$ & $\begin{array}{l}\text { Analyses the resources, markets and } \\
\text { products of ethnic sports tourism }\end{array}$ \\
\hline & $\begin{array}{l}\text { Delphi } \\
\text { method }\end{array}$ & $\begin{array}{l}\text { Determining the weights of the } \\
\text { development index system of ethnic } \\
\text { sports tourism resources }\end{array}$ \\
\hline \multirow{5}{*}{$\begin{array}{l}\text { Quantitat- } \\
\text { ive } \\
\text { analysis }\end{array}$} & $\begin{array}{l}\text { Question- } \\
\text { naire }\end{array}$ & $\begin{array}{l}\text { Investigates the situation of the } \\
\text { ethnic sports culture tourism market }\end{array}$ \\
\hline & $\begin{array}{l}\text { Analytic } \\
\text { Hierarchy } \\
\text { Process } \\
\end{array}$ & $\begin{array}{c}\text { Weights determination of suitability } \\
\text { for ethnic sports tourism } \\
\text { development }\end{array}$ \\
\hline & $\begin{array}{l}\text { Fuzzy } \\
\text { comprehe- } \\
\text { nsive } \\
\text { evaluation }\end{array}$ & $\begin{array}{l}\text { Determining the weights of the } \\
\text { development index system of ethnic } \\
\text { sports tourism resources }\end{array}$ \\
\hline & $\begin{array}{l}\text { Factor } \\
\text { analysis }\end{array}$ & $\begin{array}{l}\text { Summarises the main indicators of } \\
\text { the development potential of ethnic } \\
\text { sports tourism }\end{array}$ \\
\hline & $\begin{array}{l}\text { Cluster } \\
\text { analysis }\end{array}$ & $\begin{array}{c}\text { Categorises areas with similar } \\
\text { development potential for ethnic } \\
\text { sports tourism }\end{array}$ \\
\hline
\end{tabular}

\section{Conclusion and prospect}

Since 1998, when China began to pay attention to research on ethnic sports tourism, there have been more than 20 years of research. Choice of research case sites has been mainly on a meso-micro scale, and there is little macroscale literature. Research has mostly focused on the definition, resource evaluation, development and utilisation, brand building and marketing management of ethnic sports tourism resources. Although there has been an abundance of research, however, relevant academic research angles are relatively narrow and the content of research is comparatively simple. On the one hand, this is because in the practice of tourism development ethnic 
sports tourism has been largely neglected, and the exhibition of festival activities is still the main tourism product that tourists can participate in; on the other hand, due to cultural assimilation, the intergenerational transmission and development of ethnic sports projects have been impacted to a certain extent, which is not conducive to the development of ethnic sports tourism. In addition, a lack of professional talent and a shortage of capital investment have resulted in the inadequate development and utilisation of ethnic sports tourism. Four areas of focus for future in-depth research are proposed below.

First of all, it is necessary to introduce pluralistic theoretical research. At present, there is no integrated understanding of the basic research concepts and connotations of ethnic sports tourism. In future, we can learn from the classical and mature theoretical frameworks of ethnology, sports science, tourism, sociology and geography to promote in-depth research on ethnic sports tourism, and make up for the lack of diversity in theoretical guidance in the relevant current research, which is still at a low level. A classical and mature theoretical framework will help to open up new research ideas and perspectives, and enrich the theoretical research system of ethnic sports tourism.

Secondly, we need to pay attention to stakeholders. The development of ethnic sports tourism inevitably involves different subjects, including local residents, tourists, government and tourism enterprises. Competition between stakeholders will directly affect the sustainable and healthy development of ethnic sports tourism. However, most current research on ethnic sports tourism does not involve stakeholders. In the future, we should pay more attention to the influence of ethnic sports tourism development on local residents, tourist satisfaction and tourist motivation, government policy research, tourism enterprise marketing and social responsibility research.

Thirdly, we need to improve the quantitative evaluation of ethnic sports tourism resources. There are many kinds of ethnic sports in China, but due to the characteristics of tourism, not all ethnic sports are suitable for tourism development. Therefore, it is necessary to establish a scientific system of quantitative evaluation to ascertain the suitability of different ethnic sports for tourism resource development and utilisation, so as to provide a scientific reference for the development of ethnic sports tourism.

Finally, future research needs to explore the influence of ethnic sports tourism. The development of ethnic sports tourism has positive and negative effects on the local society, economy, culture and environment. In the future, we should focus on research on the influence of ethnic sports tourism. Combined with actual case studies, we should quantitatively analyse the impact of ethnic sports tourism, so as to expand its positive influence, reduce or avoid the negative impact of tourism development, and promote the healthy and sustainable development of ethnic sports tourism.

\section{References}

1. Finance Department. (2020) Statistical bulletin on culture and tourism development of the Ministry of culture and tourism of the people's Republic of China in

2019 , http://zwgk.mct.gov.cn/auto255/202006/t20200620_ 872736.html?keywords=.

2. Li Z, Zhong H.P, Tang J.L. (2002) Research on Exploitation of Tourism Resources in the West and the Traditional Ethnic Sports. Journal of Xi'an Institute of Physical Education 19, 2: 3-5.

3. Ming Q.Z, Liu J, Wang D.Y. (1998) Research on the Industrialization of Yunnan Ethnic Sports Tourism. Social Scientist, 6: 47-51.

4. Tian Z.G, Zhong H.P. (2002) A Study on Mutal Promotion of Tourist Industry and Traditional Minorities Sports Culture Industry. Journal of Nanjing Institute of Physical Education 16, 3: 1-3.

5. Gu T, Lu Y.Z, Yang Y.L, Zhou Z.M. (2002) Evaluation on traditional physical culture toursim resource of Guangxi minority nationality. Journal of Physical Education 9, 3: 49-51.

6. Wang G.Y, Tian H.Q, Wang J. (2007) A Research on the Development of the Traditional Ethnic Sports Tourism Resources in Enshi Tujia and Miao People Autonomous Prefecture. Journal of Physical Education Institute of Shanxi Normal University 22, 1: 83-86.

7. Li Y.H, Ling J, Zang L.H. (2003) The Development and Marketing of the Tourism Product of Traditional Minority Nationality Sports in Xinjiang. Journal of Xinjiang Education Institute 19, 2: 124-127.

8. Han H.Y. (2003) Research on the Industrialization of Qinghai National Sports Tourism. Journal of Qinghai University 21, 6: 79-81.

9. Yao X, Lu S.J, Wang Y. (2009) Study on the Sustainable Development of National Sports Tourism from the View of Anthropology of Tourism. Journal of Xi'an Physical Education University 26, 6: 699703.

10. Luan L.X, Guo J. (2006) Investigation on Development and Investment of Ethnic Minority's Traditional Sports and Tourism Market of Hubei. Journal of Xi'an Institute of Physical Education 23, 2: 58-60.

11. Li X.F. (2011) Research on the Establishment of National Sports Tourism Brand in Inner Mongolia. Journal of Shenyang Sport University 30, 1: 137-138.

12. Mi X.H, Xie Y.P. (2017) Research on Exploitation of the Minorities' Sports Resources in Yunnan in the Light of Cultural Recreation. Guizhou Ethnic Studies 38, 1: 158-161.

13. Wan P, Gai Y.J. (2017) On the Distribution and Current Development of the Sports Tourism Resources of the Ethnic Minority in Southeast Guizhou. Journal of Guizhou Education University 33, 4: 36-40. 
14. Hu Q.H, Liu R.F. (2012) Research on Classification and Development of Ethnic Traditional Sports Tourism Products in Enshi Prefecture. Journal of Hubei University for Nationalities (Philosophy and Social Sciences) 30, 6: 53-55.

15. Cheng Y, Ge X.J, Chen Z.Y. (2013) On the sustainable development of traditional sports tourism of ethnic minorities from the perspective of costing theory. Journal of Shandong Institute of Physical Education and Sports 29, 2: 24-28.

16. Han Z.Q. (2016) An Evaluation Research on the Adaptability of Traditional Ethnic Sports Tourism Development under the Perspective of Non-material Cultural Heritage in Henan. Liaoning Sport Science and Technology 38, 2: 1-5.

17. Liao X.R. (2013) Study on National Traditional Sport Tourism's Marketing Mode. Shandong University Publishing House, Jinan.

18. Liu W.Y, Wang Z. (2014) Research on the Development Model of National Sports Tourism in Southeastern Guizhou. Sports Culture Guide, 5: 117120.

19. Diao Z.D. (2009) National Traditional Sports: Delimitation and Differentiation. Journal of Shenyang Sport University 28, 6: 121-124.

20. Zhang J.X, Jiang Y.L. (2004) The Differentiation and Extent of some Related Problems of National Traditional Sports. Journal of Guangzhou Sport University 24, 5: 126-128.

21. Liu Y.F, Fei Y.H, Feng S.W, Wang C.Y, Wang W, Fei Y.G, Ju L. (2008) The Development of National Traditional Sports Tourism in Heilongjiang Province. Journal of Harbin Institute of Physical Education 26, 5: $36-38$.

22. Liu Y. (2009) Research on the Development of Folk Sports Tourism in Shandong Province. Shandong University Publishing House, Jinan.

23. Li J.R. (2014) Research on the Exploitation and Development Path of National Traditional Sports Tourism Resources-Taking Enshi Region in Southwest Hubei as an Example. Journal of Hubei Minzu University (Philosophy and Social Sciences) 32, 1: 150-152.

24. Wang T.J, Zhang X.L. (2000) Development of Tourism Resources of Minority Sports. Journal of Xinjiang Normal University (Natural sciences Edition) 19, 3: 71-75.

25. Yu F, Wu Y, Shao X.M, Hua J.W. (2013) Fuzzy Evaluation on the Suitability of Ethnic Traditional Sports Tourism Development. China Business and Trade, 8: 124-125.

26. Chen W, Wen D.N. (2011) Suitability Evaluation of Traditional Sports Tourism Development of Guangxi Minority. Journal of Chengdu Sport University 37, 10: 42-46.

27. Han Z.Q. (2016) A Study on the Suitability Evaluation of the Development of Ethnic Traditional
Sports Tourism in Henan Province. Sports, 15: 132133.

28. Fang Z.H. (2006) Analysis on Traditional Sports Tourism Resources of Lishui She Minority. Journal of Beijing Sport University 29, 10: 1325-1326.

29. Jiang W. (2008) Strategic Option on Development of Traditional Sports in Guangxi Minorities. Journal of Guilin Institute of Tourism 19, 3: 380-383.

30. Ye C.Z, Tang W.B. (2008) Research on the National Sports Travel Industry Development. Journal of Zhejiang University of Technology (Social Science) 7, 3: 290-294.

31. Liu X.G. (2010) The Research on the Development and Protection of Inner Mongolian National Minority Sport-tourism Resources. Beijing Sport University Publishing House, Beijing.

32. Nie T. (2019) Analysis on the Present Situation and Development Model of Sports Tourism in Sichuan Minority Areas. Journal of Guangzhou Sport University 39, 5: 80-83.

33. Lu Y.X. (2016) A Study on Development Model of Ethnic Traditional Sports Tourism. Guizhou Ethnic Studies 37, 10: 182-185.

34. Sun D.C. (2005) Research on Liangshan Athletic Tour Resources Development and Countermeasures. Sichuan University Publishing House, Chendu.

35. Yu W.Y, Zheng G.H, Zhu X.L. (2005) An Analysis and Prospect of Development on Guangxi Traditional Ethnic Sports Items. Journal of Tianjin University of Sport 20, 1: 28-30.

36. Zhou P, Huang Y.C. (2019) Research on the Brand of National Traditional Festival Sports TourismBased on the Tourism Survey of Nadamu in Inner Mongolia. Journal of Harbin Sport University 37, 6: 41-46.

37. Zhao M.M. (2009) On Brand Construction in the Development of Yunnan Minority Sports Tourism. Consume Guide, 19: 7-8.

38. Zhang C. (2013) Guangxi minorities traditional sports tourism market positioning and marketing research. GuangXi University for Nationalities Publishing House, Nanning.

39. Xing J.S. (2005) SWOT Analysis and Marketing of Henan Ethnologic Sports Travel. Journal of Shandong Institute of Physical Education and Sports 21, 5: 37-39.

40. Zhou C. (2016) Marketing Strategies for Traditional Sports Tourism of Ethnic Groups in the West of Guangxi. Journal of Hubei Correspondence University 29, 18: 100-101. 